\title{
Comprehensive Analysis of Pre-Charge Sequence in Automotive Battery Systems
}

\author{
Murat Kubilay Ozguc, Eymen Ipek, Kadir Aras and Koray Erhan \\ Software\&Electronics, AVL Research\&Engineering, Istanbul, Turkey
}

\begin{abstract}
Electric vehicles (EV) have brought promising technologies for future mobility solutions. As one of the key components of EVs, battery systems have fundamental functions which disconnect the battery during parking and in case of failure. To provide a safe system, specialized high voltage (HV) electromechanical switches are used to perform these major functions such as switch on, switch off or pre-charging. Due to these components can be easily damaged, expensive, heavy and bulky, a solution based on pure semiconductors may be desired to accomplish these operations. Many studies were exhibited on EV battery systems regarding developing solid-state systems for HV switchgear. Developing technology on semiconductor devices allows to make a safety concept based on only solid-state components. This study presents a comprehensive analysis of pre-charge sequences between conventional and semiconductor switchgear to be used in electric vehicle battery systems. Spice simulations are presented to investigate advantages and drawbacks of these systems.
\end{abstract}

Index Terms-electric vehicles, battery systems, li-ion, precharge, semiconductor

\section{INTRODUCTION}

Climate change concern has become a major driver for $\mathrm{CO}_{2}$ reduction regulations, and this brings the necessity of zero-emission transportation which ensures a decrease in local air pollution and noise emissions. Therefore, electric vehicles (EV) have received tremendous attention. By using $\mathrm{EVs}$, engineers and scientists not only provide a cleaner and quieter atmosphere but also drastically reduce operating costs compared to gas-powered vehicles. Electric vehicles spend approximately $0.015 \$ / \mathrm{km}$, while ICE vehicles spend $0.08 \$ / \mathrm{km}$ [1]. The increasing need for electric vehicles brought high power and energy requirements. Due to these requirements, battery packs of passenger vehicles rated at 400-600 V, sports and commercial vehicles have battery packs at the levels of 800-1000 V [2]. In addition to that, as an energy source, lithium-ion (Li-ion) batteries are utilized in electric vehicles. Usually, DC currents of approximately 300 A are needed when riding such vehicles over longer periods of time. Electric parts big in geometric size that are not simple to package in a battery scheme are needed to manage heat losses when carrying such currents. This will also lead to elevated cost and weight. EVs with voltages up to $800 \mathrm{~V}$ are currently targeted which will decrease the current levels in heavy load driving conditions. As a result, wiring and connectors are relatively small and can, therefore, overcome the issues described above. Conventional battery disconnect unit (BDU) of EV batteries basically consist of contactors, fuses, sensors, battery management system and connectors. Usage of semiconductors instead of contactors also brings the reduction of size and increase in efficiency [3]. Automotive applications require reliable systems over the lifetime in terms of mechanical shocks, vibrations, electrical instability, temperature and humidity conditions. Even tough mechanical and electro-mechanical components are proven against these, there is a chance to improve system performance. Especially in automotive high voltage (HV) battery systems, electromechanical parts can present a bottleneck. For instance, mechanical relays can require certain mounting positions considering their contact working axis.

Over the past few years, the use of SiC-based power semiconductor alternatives has shown enormous growth, relying on its revolution. The driving forces behind this growth of the industry are the following trends: saving energy, reducing the size, integrating the system and improving reliability [4]. Despite semiconductors' challenges, they can be used in automotive battery systems in lots of areas thanks to their compact design. Either pre-charge relay or main relay can be replaced by semiconductor switches. This will lead to a more reliable system in terms of vibration and shock. Also, this allows that the system is a thousand times faster for fault diagnosis and response. Besides, it is possible to decrease weight up to $60 \%$ and the volume reduction is up to $80 \%$ [5]. Studies on this subject generally present a solution which is having a semiconductor in parallel or in series to contactor [6]-[8]. On the other hand, some researches propose a method which consists a DC-DC converter in series with main relay is used for pre-charging action [9]-[11]. However, it is aimed to remove the main relay and control the power flow by using stand alone semiconductor. Moreover, the rapid progress of semiconductor technologies will enable this approach to become widespread and used in practice. At the inverter input, filter capacitors exist, that generate a severe inrush current when the circuit is closed. If this current is not limited, it may damage the cells, contactors or other battery system components. The functional requirement of the high voltage pre-charge circuit is to minimize the peak current out from the power source by slowing down the $\mathrm{dV} / \mathrm{dT}$ of the input voltage. In this paper, it is compared the characteristics of the conventional pre-charging with pre-charging with semiconductor switches by SPICE simulation results. 


\section{System PARAMETERS}

Tesla Model $\mathrm{S}$ is chosen because it is a popular vehicle and easy to reach the system specifications. The battery pack specifications of the Tesla Model S 100P is selected to determine the simulation parameters in Fig. 1. As shown in Table I, the maximum voltage of the package is 403.2 $\mathrm{V}_{\mathrm{DC}}$ within the package configuration is 16 modules in series that every module has 6 series 86 parallel cell configuration. Panasonic NCR18650B cells are used in the selected battery pack with nominal cell resistances of $18 \mathrm{~m} \Omega$ and considering the contact resistances and internal resistances of the BDU components, the total equivalent resistance of the pack is calculated as $22.10 \mathrm{~m} \Omega$ by using Eq.(1). Equivalent inductance values of the elements in the package and the cables going from the package to the inverter are accepted as $30 \mu \mathrm{H}$ in total. The values in the table are official values besides the cell inner resistance, stray inductance and DC link capacity. These values are determined according to AVL know-how.

$$
R_{\mathrm{BS}}=\left(\left(R_{\mathrm{DCIR}}+2 * R_{\mathrm{c}}\right) * \frac{n_{\mathrm{s}}}{n_{\mathrm{p}}}\right) * n_{\mathrm{m}}+R_{\mathrm{MB}}+R_{\mathrm{BDU}}
$$

where;

- $R_{B S}$ : Battery system resistance

- $R_{D C I R}$ : DC internal resistance

- $R_{c}$ : Contact resistance of the cells

- $R_{M B}$ : Module busbar resistance

- $R_{B D U}:$ BDU components' resistance

- $n_{m}$ : Number of modules

- $n_{s}$ : Number of cells in series

- $n_{p}$ : Number of cells in parallel

By using Eq.(1), Battery System Resistance is calculated as $22.10 \mathrm{~m} \Omega$. The busbar plates that make the connection of modules are accepted as they have resistance of $1 \mathrm{~m} \Omega$ and BDU components accepted as they have $1 \mathrm{~m} \Omega$ internal resistance.

TABLE I

SYSTEM PARAMETERS [12]

\begin{tabular}{ll}
\hline \hline Parameter & Value \\
\hline Vehicle Model & Tesla Model S \\
Battery Capacity & $100 \mathrm{kWh}$ \\
Pack Configuration & $16 \mathrm{MS}(6 \mathrm{~S} 86 \mathrm{P})$ \\
Nominal Cell Voltage & 3.6 \\
Maximum Cell Voltage & 4.2 \\
Cell Inner Resistance (@3.6 V) & $18 \mathrm{~m} \Omega$ \\
Nominal Pack Voltage & $345.6 \mathrm{~V}$ \\
Maximum Pack Voltage & $403.2 \mathrm{~V}$ \\
Stray Inductance & $30 \mu \mathrm{H}$ \\
Battery System Resistance & $22.10 \mathrm{~m} \Omega$ \\
DC Link Capacity (Tolerance) & $550 \mu \mathrm{F}(\mathrm{m} \% 10)$ \\
Voltage Difference & $5 \mathrm{~V}$ \\
\hline \hline
\end{tabular}

\section{Conventional Pre-CHARge}

When DC power source is applied to a capacitive load, the step response of the voltage input will cause the input capacitor to charge. The capacitor charging starts with inrush current

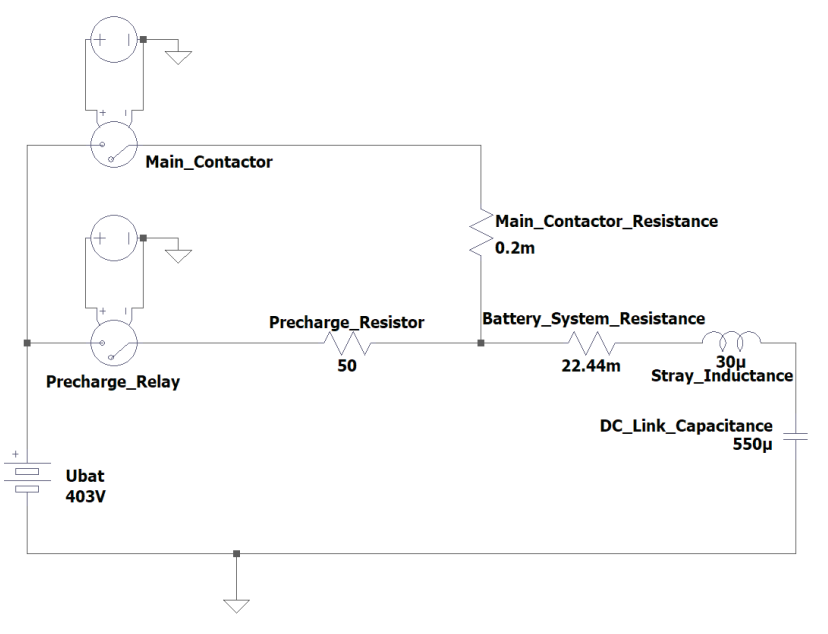

Fig. 1. Simulation circuit with contactor.

and ends with an exponential decay down to the steady state condition. The current drawn by a capacitor can be calculated by using Eq.(2).

$$
I_{\mathrm{C}}=C * \frac{d V}{d t}
$$

where;

- $I_{C}$ : Current passing through capacitor

- $C$ : DC capacitance of battery system in Farads

- $d V$ : Voltage change in Volts

- $d t$ : Time change in seconds

As can be seen in Eq.(2), the peak inrush current depends upon the capacitance $\mathrm{C}$ and the rate of change of the voltage $(\mathrm{dV} / \mathrm{dT})$. The functional requirement of the high voltage precharge circuit is to minimize the peak current out from the power source by slowing down the $\mathrm{dV} / \mathrm{dT}$ of the input power voltage. Upon completion of the pre-charging sequence, the pre-charge resistor is switched out of the power supply circuit and returns to a low impedance power source for normal mode. In order to find inrush current, pre-charge resistor value can be calculated with Eq.(3). In this simulation, pre-charge time is decided as $120 \mathrm{~ms}$ and voltage difference between DC-Link capacitor and battery pack is determined as $5 \mathrm{~V}$. With precharge time of $120 \mathrm{~ms}$, pre-charge resistance is calculated as $49.79 \Omega$ using Eq.(3). However, in the simulation, it is rounded up to $50 \Omega$.

$$
R_{\text {pre }}=-\frac{t}{C * \ln \left(\frac{\Delta U}{U_{\text {Bat } \text { max }_{\text {ax }}}}\right)}
$$

where;

- $R_{\text {pre }}$ : Resistance value of pre-charge resistor in $\Omega$

- $\Delta U$ : Voltage change in Volts

- $U_{\text {Bat.max }}$ : Maximum battery system voltage in Volts

In the simulation circuit, the capacity value is taken as 550 $\mu \mathrm{F}$ and start of the sequence have $10 \mathrm{~ms}$ delay to get a coherent output on graphs. The result of the simulation circuit shown in Figure 1 can be seen in Fig. 2, the capacity voltage has 
reached $398 \mathrm{~V}$ within $120 \mathrm{~ms}$. At the end of $180 \mathrm{~ms}$, there is no voltage difference between the capacity and the battery pack. Meanwhile, the pre-charge current reaches the peak value of $8 \mathrm{~A}$ at the start time (i.e. $10 \mathrm{~ms}$ ), then exponentially reduces and cuts off around $180 \mathrm{~ms}$.

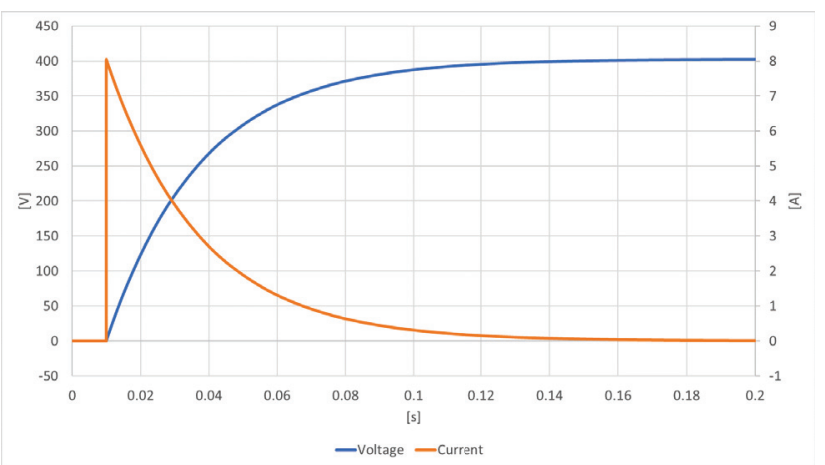

Fig. 2. Simulated pre-charge waveforms.

As shown in Fig. 3, the maximum power dissipated on precharge resistor is $3.25 \mathrm{~kW}$. Consequently, in $120 \mathrm{~ms}$ sequence total energy loss is $44.71 \mathrm{Ws}$.

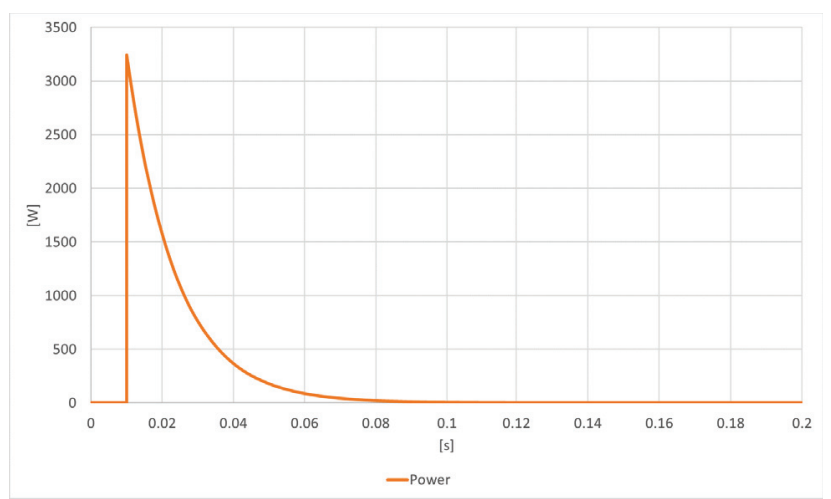

Fig. 3. Power dissipation on pre-charge resistor.

\section{PRE-Charge With Semiconductor}

On the other hand, the pre-charge sequence can be achieved by using semiconductor switches. A silicon-based switch allows not only removing pre-charge contactor but also resistor. At low to medium power levels which require few hundred volts of blocking capability, MOSFETs are ideal semiconductors to use in this application because they are capable of fast switching time against majority carrier devices, lower switching loss due to fast rise and fall times, uncomplicated gate drive and low $\mathrm{R}_{\mathrm{DS} \text { (on) }}$ to increase the efficiency by decreasing the voltage drop during steady state operation. Since this is an only a new and innovative method can be applied, it is assumed that only a single MOSFET to use which's parameters can be seen in Table II. However, to cover power ratings of general battery packs, semiconductors in the market need to be used in parallel.
TABLE II

SElected MOSFET PARAmeters [13]

\begin{tabular}{lll}
\hline \hline Parameter & Value & Unit \\
\hline $\mathrm{V}_{\mathrm{DS}}$ & 650 & $\mathrm{~V}$ \\
$\mathrm{R}_{\mathrm{DS}(\mathrm{on})}$, Max & 0.048 & $\Omega$ \\
Continuous Drain Current $\left(\mathrm{T}_{\mathrm{c}}=100 \mathrm{C}\right)$ & 40 & $\mathrm{~A}$ \\
Pulsed Drain Current $\left(\mathrm{T}_{\mathrm{c}}=25 \mathrm{C}\right)$ & 228 & $\mathrm{~A}$ \\
Power Dissipation & 500 & $\mathrm{~W}$ \\
\hline \hline
\end{tabular}

Because of being automotive compatible, having low Onresistance and covering voltage spikes with its high voltage rating of $650 \mathrm{~V}$, Infineon IPW65R048CFDA MOSFET model is used in these SPICE simulations which can be seen in Fig. 4.

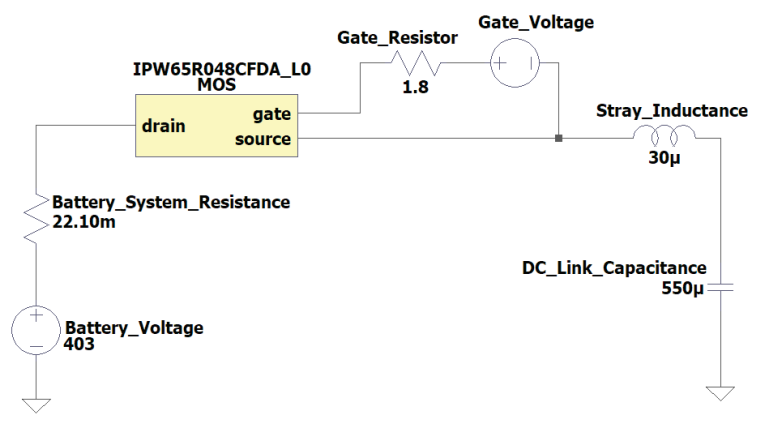

Fig. 4. Simulation circuit with semiconductor.

\section{A. Pre-charging with PWM Method}

The capacitor charge can be done via PWM switching of semiconductors since a switching action will block inrush currents from the battery until the difference is acceptable. After the capacitors reached a certain voltage level, semiconductors can be turned-on fully. As seen in Fig. 5, DC link voltage rises while pre-charge current stays at same level with approximately $10 \mathrm{~A}$ in MOSFET's on state.

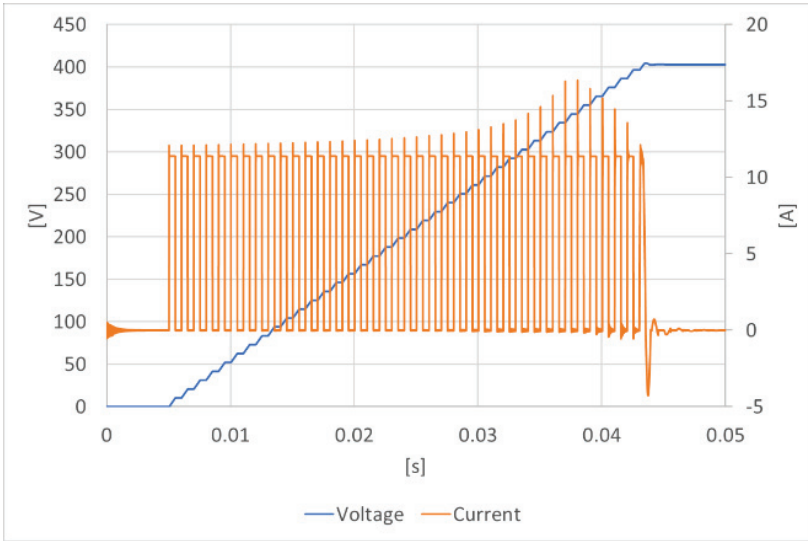

Fig. 5. PWM method DC-Link capacitance waveforms.

This method can adjust the peak value of inrush current and settling time by PWM control sequence of MOSFET as shown in Fig. 6. However, it has a limitation due to switching losses of PWM operation and needs proper heatsink design. 


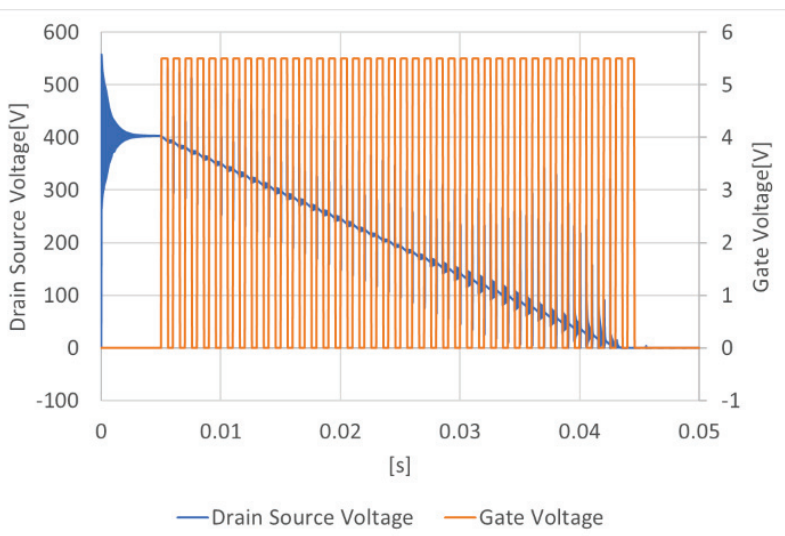

Fig. 6. MOSFET voltage waveforms.

As shown in Fig. 7, the maximum power dissipated on MOSFET during PWM operation reaches to $5.275 \mathrm{~kW}$ peak. Consequently, in $40 \mathrm{~ms}$ sequence, total energy loss is 44.60 Ws.

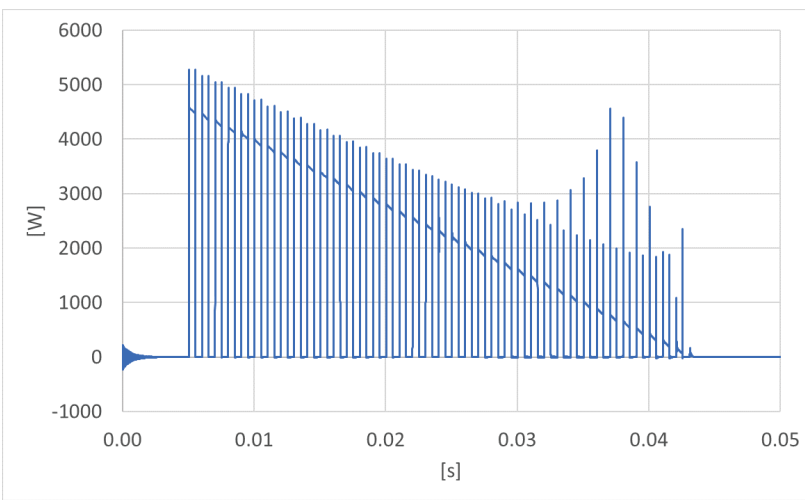

Fig. 7. Power dissipation on MOSFET.

\section{B. Pre-charging with Controlling the Turn-on Switching of MOSFET}

Limitation of inrush current comes from the gate charge characteristic of MOSFET when the device is turned on. The gate charge characteristic is originated from the equivalent capacitance of the MOSFET [14]. The quicker the capacitance is charged and discharged will dictate the easier the system turns on or off. The most efficient way to obtain and control the MOSFET switching mechanism is by using the gate-charge transfer curves provided on datasheet [15].

Fig. 8 shows the turn-on gate-charge transfer curve from SPICE simulation. This curve shows how the voltage curve pattern of $V_{G S}$ and $V_{D S}$ changes for limiting the drain current which is also same current that flows through dc-link capacitor.

Pre-threshold region and the constant current are used for rising of $\mathrm{V}_{\mathrm{GS}}$ to device threshold voltage $\mathrm{V}_{\text {th }}$ at a linear slope. When $V_{G S}$ has reached the $V_{\text {th }}$, the drain current rises to its steady state region. After that, the drain-source voltage starts its transition and the gate-charge transfer curve starts to

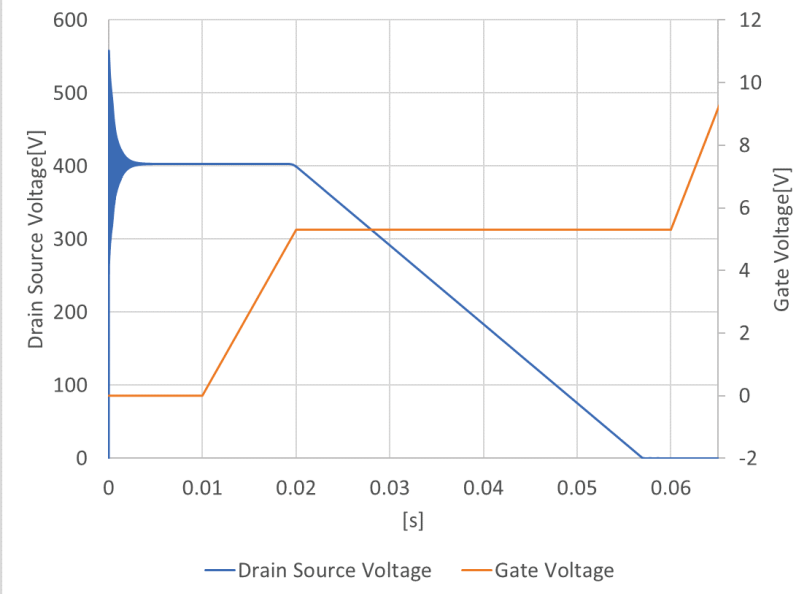

Fig. 8. MOSFET gate charge transfer curve.

level off. As the voltage across the drain-gate reduces even more. DC Link capacity voltage as can be seen in Fig. 9 reaches its expected value. Gate voltage is increased and MOSFET starts conduct as full on mode. Since changes in drain-source voltage affects drain current, the pre-charging time collaborates with gate voltage directly. The drain voltage control capability will allow the $\mathrm{dV}_{\mathrm{DS}} / \mathrm{dt}$ to be fully controlled independently of the load condition. The ability to control $\mathrm{dV}_{\mathrm{DS}} / \mathrm{dt}$ will allow the capacitive load or resistive load to be controlled by the inrush current [7].

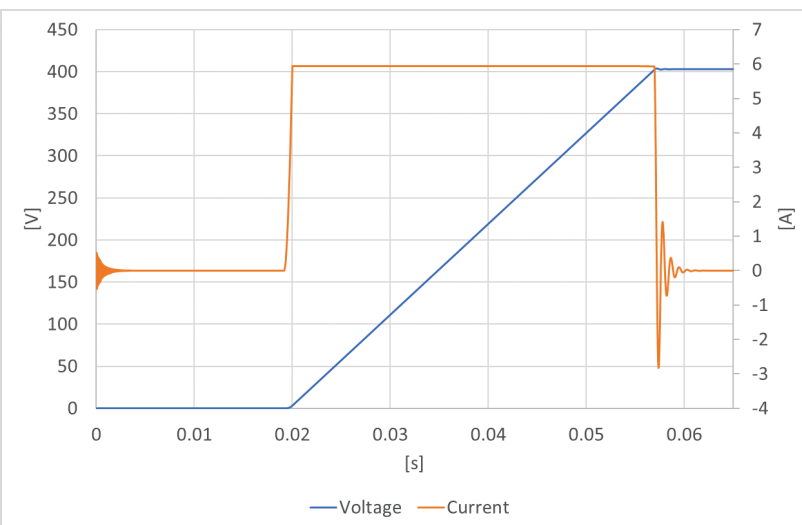

Fig. 9. Linear mode method DC-Link capacitance waveforms.

As shown in Fig. 10, the maximum power dissipated on MOSFET during Turn-on switching operation reaches to 2400 $\mathrm{kW}$ peak. Consequently, in $40 \mathrm{~ms}$ sequence total energy loss is $44.65 \mathrm{Ws}$.

Oscillations which are seen in Fig. 5, 6, 7, 8, 9 will occur in real system. Therefore, it is necessary to use snubber circuit for absorbing oscillations during switching in experimental studies. 


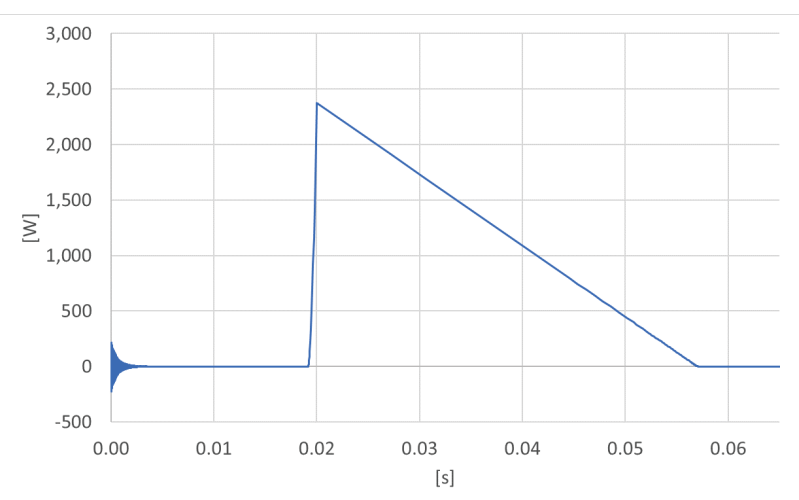

Fig. 10. Power dissipation on MOSFET.

\section{CONCLUSION}

As shown in Table III, pre-charge sequence can be performed $80 \mathrm{~ms}$ faster by using semiconductor, while maximum power loss varies depending on which active pre-charge method is used. In contrast to the $2.34 \mathrm{~kW}$ power dissipation value of the pre-charge sequence with the conventional resistance, peak values reach the value of $5.28 \mathrm{~kW}$ in the PWM method and $2.38 \mathrm{~kW}$ in turn-on control method. Since the energy stored in the capacitor depends on voltage applied and the capacity of capacitor, in all 3 simulations energy losses are similar. However, in addition to these results, it should be taken into consideration that semiconductor solutions will be much lighter and take up less space than mechanical relay solutions. On the other hand, semiconductor switchgears need cooling unlike mechanical relays. According to all findings in this paper, it can be clearly seen that the usage of stand-alone semiconductor switch gear empowers pre-charging action in automotive battery systems with its notable advantages compared to a conventional mechanical relay system. Moreover, solid-state technology is more reliable against mechanical shocks, electrical abnormalities, and environmental conditions. Besides, there is no strict requirement of mounting of solid-state circuits. Semiconductors can react in microseconds during electrical failures. Thanks to superiorities of semiconductors comparing electro-mechanical parts, one can say that they will surpass their current usage areas. In the near future, they will be used in many additional areas as well as automotive battery systems.

\section{REFERENCES}

[1] Siang Fui Tie, Chee Wei Tan "A review of energy sources and energy management system in electric vehicles", Renewable and Sustainable Energy Reviews, vol. 20, pp 82-102, April 2013.

[2] ZVEI, "Voltage cases for electric mobility" p. 11-12. Available: zvei.org/fileadmin/user_upload/Presse_und_Medien/Publikationen/ 2014/april/Voltage_Classes_for_Electric_Mobility/Voltage_Classes_for_ Electric_Mobility.pdf [Accessed November 20, 2019].

[3] AVL Trimerics GmbH, High Performance 800v E-Motor for Automotive Application, Available: https://bit.ly/2k9Q4YS [Accessed November 20, 2019].

[4] Friedrichs, P., Buschkuehle, M. (2016). The Future of Power Semiconductors : Rugged and High Performing Silicon Carbide Transistors.
TABLE III

COMPARISON BETWEEN SWITCHGEARS

\begin{tabular}{|c|c|c|c|}
\hline \multirow[b]{2}{*}{ Parameter } & \multirow{2}{*}{$\begin{array}{c}\text { Mechanical } \\
\text { Relay } \\
\text { Pre-Charge } \\
\text { Resistor }\end{array}$} & \multicolumn{2}{|c|}{$\begin{array}{l}\text { Semiconductor } \\
\text { Switchgear }\end{array}$} \\
\hline & & PWM Method & $\begin{array}{c}\text { Turn-On } \\
\text { Control Method }\end{array}$ \\
\hline Time [ms] & 120 & 40 & 40 \\
\hline $\begin{array}{l}\text { Maximum Power } \\
\text { Dissipation [kW] }\end{array}$ & 3.24 & 5.28 & 2.38 \\
\hline $\begin{array}{l}\text { Energy Loss } \\
\text { [Ws] }\end{array}$ & 44.71 & 44.60 & 44.65 \\
\hline Volume [1] & $>1$ & \multicolumn{2}{|c|}{$<1$} \\
\hline Weight $[\mathrm{Kg}]$ & $>1$ & \multicolumn{2}{|c|}{$<1$} \\
\hline Cooling & Not necessary & \multicolumn{2}{|c|}{ Required } \\
\hline
\end{tabular}

[5] Rößler, Werner. "When Do We Get the Electronic Battery Switch?.' In Advanced Microsystems for Automotive Applications 2014, pp. 165177. Springer, Cham, 2014.

[6] Parrish, R., Elankumaran, K., Gandhi, M., Nance, B., Meehan, P., Milburn, D., ... \& Brenz, A. (2011). Voltec battery design and manufacturing (No. 2011-01-1360). SAE Technical Paper.

[7] Mensah-Brown, A. K., Hashim, H. R., Blakemore, B. C., \& Gale, A. R. (2017). U.S. Patent No. 9,573,474. Washington, DC: U.S. Patent and Trademark Office.

[8] Burkman, W. E., \& Sturza, J. (2018). U.S. Patent Application No. $15 / 469,012$.

[9] Soldati, A., Imamovic, E., \& Concari, C. (2019). Bidirectional Bootstrapped Gate Driver for High-density SiC-based Automotive DC/DC Converters. IEEE Journal of Emerging and Selected Topics in Power Electronics.

[10] Blakemore, B. C., Gale, A. R., Degner, M. W., Mensah-Brown, A. K., \& Wang, C. L. (2015). U.S. Patent Application No. 14/250,231.

[11] Mensah-Brown, A. K., Gale, A. R., Blakemore, B. C., \& Wang, C. L. (2017). U.S. Patent No. 9,796,288. Washington, DC: U.S. Patent and Trademark Office

[12] Tesla Motors. "Tesla Model S. Palo Alto" Available: http://my. teslamotors.com/de \_DE/models/design, [Accessed 2015].

[13] Infineon, "650V CoolMos CFDA Power Transistor" IPW65R048CFDA datasheet, Mar. 2012.

[14] Lee, Eun-Ju, Jung-Hoon Ahn, Seung-Min Shin, and Byoung-Kuk Lee. "Comparative analysis of active inrush current limiter for high-voltage DC power supply system." In IEEE Vehicle Power and Propulsion Conference 2012, pp. 1256-1260. IEEE 2012.

[15] Motorola Inc, Applitaction Note AN1542. 


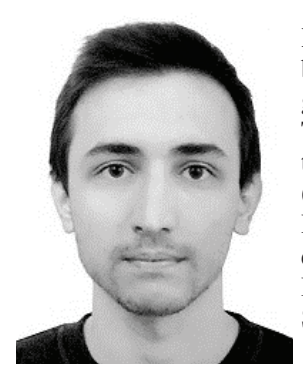

Kubilay OZGUC was born in 1996 in Istanbul/Turkey. He received his BSc in Electrical Engineering from Yıldız Technical University (YTU), Turkey in 2018. Then he started to his MSc in Electrical Engineering at Istanbul Technical University (ITU) in 2019 and he is a MSc student in ITU. He had worked on power electronics and renewable energy during his BSc. He is currently working as Battery Development Engineer in the field of Battery Systems at AVL R\&D Company, Turkey.

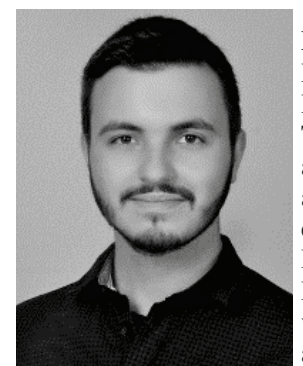

Eymen IPEK was born in 1995 in Istanbul/Turkey. He received his BSc in Electrical Engineering from Istanbul Technical University (ITU), Turkey in 2017. Then he started to his MSc in Electrical Engineering at Istanbul Technical University in 2017 and he is a MSc student in ITU. He had worked on power electronics, electric \& hybrid electric vehicles, LiIon batteries and battery systems topics during his BSc. He is currently holding position of Battery Development Engineer in the field of Battery Systems at AVL R\&D Company, Turkey. He has published 2 papers about battery systems for electric \& hybrid electric vehicles.

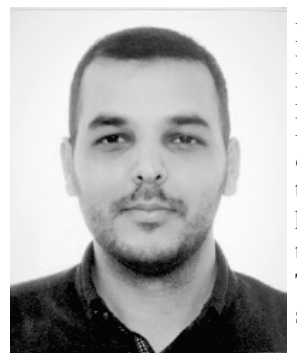

Kadir ARAS was born in 1994 in Antalya/Turkey. $\mathrm{He}$ received his BSc in Electrical Engineering from Istanbul Technical University (ITU), Turkey in 2018. $\mathrm{He}$ had worked on renewable energy sources, electric \& hybrid electric vehicles, Li-Ion batteries and battery systems topics during his BSc. He is currently holding position of Battery Development Engineer in the field of Battery Systems at AVL R\&D Company, Turkey. He has published 1 paper about battery systems for electric \& hybrid electric vehicles.

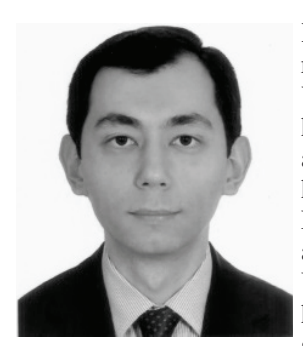

Koray ERHAN was born in 1987 in Turkey. He received his BSc in Electrical Engineering from Yildiz Technical University, Turkey in 2010. Then he completed his MSc in Electrical Engineering at Istanbul Technical University in 2013. Finally, he got his PhD at Department of Energy Systems Engineering, Kocaeli University in 2018. He became a research assistant in 2010 at Istanbul Technical University and in 2013 at Kocaeli University. He has published more than 30 papers in different subjects including electric \& hybrid electric vehicles photovoltaic power generation systems, renewable energy sources, energy storage technologies, and smart grid integration and automation systems. He has been a referee in SCI and other indexed journals. He is currently holding position of Battery Development Engineer at AVL R\&D Company, Turkey. 